American Journal of Agricultural and Biological Sciences 5 (2): 177-182, 2010

ISSN 1557-4989

(C) 2010 Science Publications

\title{
Identification of Volatile Metabolites from Fungal Endophytes with Biocontrol Potential towards Fusarium oxysporum F. sp. cubense Race 4
}

\author{
${ }^{1,2}$ A.S.Y. Ting, ${ }^{1}$ S.W. Mah and ${ }^{1}$ C.S. Tee \\ ${ }^{1}$ Department of Science, Faculty of Engineering and Science, \\ University Tunku Abdul Rahman, Kuala Lumpur, Malaysia \\ ${ }^{2}$ School of Science, Monash University Sunway Campus, Jalan Lagoon Selatan, \\ 46150 Bandar Sunway, Selangor Darul Ehsan, Malaysia
}

\begin{abstract}
Problem statement: Fungal endophytes are widely studied for their potential as biocontrol agents towards fungal pathogens. In vitro assessments usually reveal their antibiosis and mycoparasitism nature, but little is understood regarding their production of volatile metabolites as mechanisms of antagonism. Approach: This study explored the potential of fungal endophytes in controlling the pathogen responsible for Fusarium wilt disease. Nine fungal endophytes were tested for their ability to inhibit the growth of the pathogenic Fusarium oxysporum F. sp. cubense race 4 (FocR4) via production of volatile inhibitory metabolites. The type of volatile metabolites produced were subsequently characterized and identified using the Gas-Chromatography Mass-Spectrophotometry (GCMS). Results: Eight of the isolates (BTF05, BTF07, BTF08, BTF15, BTF21, WAA03, WAA02, MIF01) showed positive results with percentages of inhibition varying from $1.43-31.43 \%$ while one isolate (ALF01), showed negative result (0\% inhibition). Volatile profiles showed that these fungal endophytes produced between 15-47 volatile metabolites per isolate. However, the more volatile metabolites produced by a single endophyte does not indicate better biocontrol potential. Isolate BTF05 produced 47 different volatile metabolites, but has only $8.57 \%$ inhibition, compared to isolate BTF21 with 15 metabolites but a percentage of $11.43 \%$ inhibition. The potency of the volatile metabolites produced may also influenced the biocontrol potential of the fungal endophytes as some isolates such as BTF08 and MIF01 have only two to three known inhibitory metabolites but have higher PIDG values at 31.43 and $11.43 \%$, respectively. Contrary, isolates WAA02 and WAA03 which has five to six metabolites but PIDG values of less than 3\%. Conclusion: Fungal endophytes have the ability to produce several types of volatile metabolites to inhibit the growth of FocR4. These volatile inhibitory metabolites can be further extracted and the amount produced ascertained for future manipulation in biological control of FocR4.
\end{abstract}

Key words: Endophytes, Fusarium wilt, gas-chromatography mass-spectrophotometry, volatile metabolites

\section{INTRODUCTION}

Endophytes are most often isolated from symptomless plants of various species (McInroy and Kloepper, 1995). Their association with host plants are known to improve plant growth and vigour (Ting et al., 2008), enhance plant nutrient absorption (Chanway, 1996) and to potentially confer disease resistance in plants against pathogen infection (Ting et al., 2007). Similar to other soil-borne biocontrol agents, endophytes also produce the following biocontrol activity-production of antimicrobial compounds, competition for colonizing sites and nutrients and stimulation of host defenses; as their mechanisms of inhibition towards various pathogens (Benhamou et al., 2000; Larkin et al., 1996; Pleban et al., 1995).

Of the many mechanisms of pathogen inhibition, production of antimicrobial compounds is the most easily detected and widely studied. Antimicrobial compounds are produced in either volatile or nonvolatile forms (Brooks et al., 1994; Cazar et al., 2005; Chanway, 1996; Chaurasia et al., 2005). The nonvolatile compounds are often detected using simple plate assay (Chaurasia et al., 2005) and the filtrates can be easily extracted, purified and characterized

Corresponding Author: A.S.Y. Ting, School of Science, Monash University Sunway Campus, Jalan Lagoon Selatan, 46150 Bandar Sunway, Selangor Darul Ehsan, Malaysia Tel: 603-5514 6105 Fax: 603-5514 6364 
(Liu et al., 2007). As a result, many non-volatile inhibitory compounds from fungal endophytes have been identified. This includes viridiofungin A secreted by Trichoderma harzanium (El-Hasan et al., 2009), production of hydrogen peroxide by glucose oxidase enzyme of Talaromyces flavus (Naraghi et al., 2008) and aflatoxin secreted by Aspergillus flavus (Adebanjo and Bankole, 2004).

Contrary, the extraction, characterization and identification of volatile compounds produced by fungal endophytes can only be studied using more sophisticated means, such as with the use of GasChromatography Mass-Spectrophotometry (GC-MS) (Strobel et al., 2001). As such, studies on beneficial inhibitory volatile metabolites are relatively new (Chen et al., 2008; El-Hasan et al., 2009; Fernando et al., 2005). Nevertheless, the role of volatile inhibitory compounds in biological control remains to be investigated and may have tremendous potential as the volatile compounds can be entrapped or immobilized in bioformulations and manipulated for applications in the field or for post-harvest disease management (misting, spraying and droplets). Applications using volatile metabolites also exclude the introduction of viable cells, eliminating the unnecessary or accidental introduction of foreign microbes into the environment

In present study, we identified the different types of volatile compounds produced by the fungal endophytes and distinguished between volatiles which may have inhibitory effect towards the fungal pathogen Fusarium oxysporum F. sp. cubense race 4 (FocR4). Comparisons to literatures also enabled the identification of several compounds, which are established antifungal compounds. The profile of volatile compounds produced by these fungal endophytes can then be used for possible selection and manipulation in biological control implementations in the future.

\section{MATERIALS AND METHODS}

Isolate preparation: Nine fungal endophytes (BTF05, BTF07, BTF08, BTF15, BTF21, WAA02, WAA03, MIF01 and ALF01) used in this study were previously isolated from the stem tissues of Musa spp. (BTF05, BTF07, BTF08, BTF15, BTF21), grass weeds (WAA02, WAA03), Mimosa pudica (MIF01) and Allamanda spp. (ALF01). Isolation was performed using methods by (Hallmann et al., 1997). The pure cultures obtained were maintained on Potato Dextrose Agar (PDA) (Merck) at room temperature $\left(28 \pm 3^{\circ} \mathrm{C}\right)$. The fungal endophytes were identified to their genus level by morphological characterization using slide cultures. The fungal pathogen Fusarium oxysporum F. sp. cubense race 4 (FocR4) from VCG 01213/16 (Bentley et al., 1998) was obtained from Prof. Dr. Sariah Meon from University Putra Malaysia as cultures established on PDA.

Detection of inhibitory activity by volatiles produced by fungal endophytes: Double-plate assay was performed to determine the inhibitory potential of fungal endophytes towards FocR4 via production of volatile inhibitory metabolites. The fungal cultures (including FocR4) were first established as pure cultures on PDA plates for 5 days. The PDA plates containing FocR4 were then placed inversely over the plates cultivated with fungal endophytes. The cover lids for the petri dishes were removed and both plates were then sealed together with parafilm. The plates were incubated at room temperature $\left(28 \pm 3^{\circ} \mathrm{C}\right)$ for 7 days. For control, plates containing fungal endophytes were inoculated instead with plain agar plugs. Growth inhibition of FocR4 by volatiles produced by fungal endophytes was assessed based on the Percentage of Inhibition of Diameter Growth (PIDG). The PIDG values were observed for 7 days and calculated as follows (Trivedi et al., 2008):

$$
\operatorname{PIDG}(\%)=\frac{\mathrm{D} 1-\mathrm{D} 2}{\mathrm{D} 1} \times 100 \%
$$

Where:

D1 = Diameter growth of FocR4 exposed to plain agar plug (control)

D2 = Diameter growth of FocR4 exposed to fungal endophytes

The plate assay was conducted in a complete randomized design, with three replicates and repeated once.

Detection of volatile compounds produced: The fungal endophytes were first established as pure cultures on PDA. After 7 days of incubation at room temperature, the volatiles produced by the fungal endophytes were collected using the Solid-Phase Micro-Extraction (SPME) technique (Strobel et al., 2001; Ting et al., 2007; 2008; Trivedi et al., 2008; Wan et al., 2008). The SPME technique detects all types of volatile compounds produced at the headspace above the fungal cultures and do not discern between inhibitory and non-inhibitory volatiles. To collect the volatile compounds, a small hole, adequate to accommodate the size of the SPME syringe was first gently forced into the side of the Petri 
dish using a sterile needle. The SPME syringe (Supelco), with divinylbenzene/carburen on polydimethylsiloxane fiber material (50/30) (on a $65 \mu \mathrm{m}$ stable flex fiber), was then inserted through the hole. The syringe was exposed to the volatiles in the headspace for $40 \mathrm{~min}$, allowing volatiles to entrap to the fiber material. The sample in the syringe was then transferred to a GC-MS (Shimadzu GCMS QP2010) for analysis. Volatile samples were analyzed with the following conditions: $40^{\circ} \mathrm{C}$ for $2 \mathrm{~min}$ for initial temperature, gradually increasing to 150 at $20^{\circ} \mathrm{C} \mathrm{min}{ }^{-1}$ and then to $280^{\circ} \mathrm{C}$ at $100^{\circ} \mathrm{C} \mathrm{min}^{-1}$ and finally programmed at $280^{\circ} \mathrm{C}$ for $2 \mathrm{~min}$. Helium was used as the carrier gas with a flow velocity of $1 \mathrm{~mL} \mathrm{~min}{ }^{-1}$. For control, volatile compounds were collected from the headspace of a non-inoculated agar plate. Identification of the volatile compounds was performed by comparing with the National Institute of Standards and Technology (NIST) database on the mass spectrometer (Strobel et al., 2001; Ting et al., 2007; 2008; Trivedi et al., 2008; Wan et al., 2008). The GCMS analysis was repeated once.

\section{RESULTS}

Inhibition via production of volatile metabolites: Of the nine isolates tested, eight isolates showed inhibitory effect towards FocR4. Five of the eight isolates (BTF05, BTF07, BTF15, WAA02, WAA03) showed weak inhibitory effect towards FocR4 with PIDG values less than $10 \%$, while three isolates (BTF08, BTF21 and MIF01) produced PIDG values more than $10 \%$. The strongest inhibitory effect was produced by fungal endophyte BTF08 with $31.43 \%$ (Table 1). In addition, preliminary investigations based on the morphology of the isolates suggested that isolate BTF05 belonged to the class Basidiomycetes, BTF07 is presumptively a Geotrichum spp., BTF08 and BTF15 as Penicillium spp., BTF21 as a Botrytis spp. and MIF01 as a Cladosporium spp. The isolates WAA02 and WAA03 were unidentified as these isolates did not produce sporing structures on PDA.

Volatile compounds produced by fungal endophytes: The fungal endophytes produced a variety of volatile metabolites, ranging from 15-47 different volatile metabolites per isolate. To determine potential inhibitory volatile compounds, comparisons were made between the volatile profiles of the fungal endophytes with profiles from control and ALF01 to eliminate noninhibitory volatiles. An average of six compounds were detected from both profiles of control and fungal endophytes. These compounds were eliminated, as they were considered as compounds non-induced by fungal endophytes. This includes mostly diethyl phthalate, hexane, 2-propanone 1-(1-methylethoxy), pentane 2methyl, ethyl alcohol and ethyl ether with 29.16, 14.64, $10.45,5.87,5.75$ and $3.34 \%$ peak area, respectively (results not shown). The fungal endophyte ALF01 has 23 compounds, of which two to five of the compounds were also detected in the profiles of other fungal endophytes with varying percentages of peak areas. These include nitrous oxide, 1,3,5-cycloheptatriene, 1,3,5,7-cyclooctratetraene, cyclopropane, 2,4,6-tris (1,1-dimethylethyl) and carbon dioxide (data not shown). These compounds were considered as noninhibitory as well as their production by ALF01 did not inhibit the growth of FocR4.

As such, only less than half of the volatile metabolites produced by the fungal endophytes have the potential to inhibit FocR4 (Table 1). Results also showed that the more volatiles produced, does not necessary indicate a stronger inhibitory effect. Isolate BTF05 with 29 potential inhibitory volatiles, produced only $8.57 \%$ PIDG value. Contrary, isolate BTF08 with only 13 potential volatile inhibitors produced the highest PIDG value of $31.43 \%$ (Table 1). This showed that the type of volatiles produced by the isolates may have influenced the inhibitory effect towards FocR4.

Analysis on the volatile profiles showed that several volatile compounds were detected consistently in several isolates with inhibitory effect towards FocR4 (Table 2). The most common volatile compounds were butane 2-methyl, 1-butanol 3-methyl, 1,4-methano-1Hcyclopropa [d] pyridazine, $\beta$-butyrolactone and 2 butenedinitrile, found in the most number of fungal endophytes (Table 2). These compounds, except for 1butanol 3-methyl, were rather potent as with peak areas of less than $10 \%$, they were able to inhibit the growth of FocR4 effectively (up to $31.43 \%$ PIDG) (Table 2). Several other compounds known to have antifungal properties were also detected in the profiles of the endophytes. These compounds include glycidol, 2acetyl-5-methylfuran, acetic acid pentyl ester, 1propanol 2-methyl, 1-butanol 2-methyl, furan 2methoxy and $\alpha$-phellandrene (Table 2). Glycidol and 2acetyl-5-methylfuran were exclusive to isolate BTF05, while acetic acid pentyl ester and 1-butanol 2-methyl was produced only by isolates BTF07 and WAA03, respectively. The other compounds, 1-propanol 2meythl, furan 2-methyl and $\alpha$-phellandrene were detected in more than two isolates.

Analysis based on isolates and the number of compounds produced concur that the more volatiles produced does not necessary lead to better inhibition of FocR4. Isolates BTF08, BTF21 and MIF01 with PIDG 
Am. J. Agri. \& Biol. Sci., 5 (2): 177-182, 2010

Table 1: Fungal endophytes with their respective PIDG (\%) values and number of volatiles compounds detected according to each category

\begin{tabular}{|c|c|c|c|c|c|c|}
\hline Culture & PIDG (\%) & $\begin{array}{l}\text { Total volatiles } \\
\text { detected }\end{array}$ & $\begin{array}{l}\text { No. of compounds } \\
\text { detected in control }\end{array}$ & $\begin{array}{l}\text { No. of compounds } \\
\text { detected in ALF01 }\end{array}$ & $\begin{array}{l}\text { No. of unidentified } \\
\text { compounds }\end{array}$ & $\begin{array}{l}\text { Total potential } \\
\text { inhibitory compounds }\end{array}$ \\
\hline BTF05 & 8.57 & 47 & 7 & 4 & 7 & 29 \\
\hline BTF07 & 7.14 & 35 & 5 & 3 & 9 & 18 \\
\hline BTF08 & 31.43 & 25 & 5 & 5 & 2 & 13 \\
\hline BTF15 & 7.14 & 28 & 5 & 4 & 8 & 11 \\
\hline BTF21 & 11.43 & 15 & 6 & 2 & 0 & 7 \\
\hline WAA02 & 2.86 & 34 & 9 & 3 & 1 & 21 \\
\hline WAA03 & 1.43 & 25 & 7 & 2 & 0 & 16 \\
\hline MIF01 & 11.43 & 31 & 10 & 3 & 5 & 13 \\
\hline ALF01 & 0.00 & 23 & 6 & NA & 7 & 0 \\
\hline Control & NA & 23 & NA & 6 & 2 & 0 \\
\hline
\end{tabular}

Note: NA: Not Applicable

Table 2: Volatile compounds detected in the profiles of the respective fungal endophytes and their corresponding peak areas (\%)

\begin{tabular}{|c|c|c|c|c|c|c|c|c|}
\hline \multirow[b]{2}{*}{ Isolates } & \multicolumn{8}{|c|}{ Peak areas $(\%)$} \\
\hline & BTF05 & BTF07 & BTF08 & BTF15 & BTF21 & WAA02 & WAA03 & MIF01 \\
\hline \multicolumn{9}{|l|}{ Compounds } \\
\hline Butane 2-methyl & 0.51 & $\mathrm{x}$ & $\mathrm{x}$ & 4.56 & 2.37 & $\mathrm{x}$ & $\mathrm{x}$ & 6.45 \\
\hline 1-butanol, 3-methyl & 9.90 & 21.24 & 1.40 & $\mathrm{x}$ & $\mathrm{x}$ & 14.47 & 1.04 & $\mathrm{x}$ \\
\hline $\begin{array}{l}\text { 1,4-methano-1H-cyclopropa[d] } \\
\text { pyridazine }\end{array}$ & 0.14 & 0.31 & $\mathrm{x}$ & $\mathrm{x}$ & $\mathrm{x}$ & 0.64 & 0.33 & $\mathrm{x}$ \\
\hline$\beta$-butyrolactone & $\mathrm{x}$ & $\mathrm{x}$ & 4.77 & 4.96 & 3.19 & 0.54 & $\mathrm{x}$ & $\mathrm{x}$ \\
\hline 2-butenedinitrile & $\mathrm{x}$ & $\mathrm{x}$ & 2.05 & 1.22 & 1.88 & $\mathrm{x}$ & 2.19 & $\mathrm{x}$ \\
\hline glycidol & 0.33 & $\mathrm{x}$ & $\mathrm{x}$ & $\mathrm{x}$ & $\mathrm{x}$ & $\mathrm{x}$ & $\mathrm{x}$ & $\mathrm{x}$ \\
\hline 2-acetyl-5-methylfuran & 1.68 & $\mathrm{x}$ & $\mathrm{x}$ & $\mathrm{x}$ & $\mathrm{x}$ & $\mathrm{x}$ & $\mathrm{x}$ & $\mathrm{x}$ \\
\hline acetic acid pentyl ester & $\mathrm{x}$ & 1.08 & $\mathrm{x}$ & $\mathrm{x}$ & $\mathrm{x}$ & $\mathrm{x}$ & $\mathrm{x}$ & $\mathrm{x}$ \\
\hline 1-propanol 2-methyl & 2.76 & 3.76 & $\mathrm{x}$ & $\mathrm{x}$ & $\mathrm{x}$ & $\mathrm{x}$ & $\mathrm{x}$ & 3.61 \\
\hline 1-butanol 2-methyl & $\mathrm{x}$ & $\mathrm{x}$ & $\mathrm{x}$ & $\mathrm{x}$ & $\mathrm{x}$ & $\mathrm{x}$ & 2.95 & $\mathrm{x}$ \\
\hline Furan 2-methoxy & $\mathrm{x}$ & $\mathrm{x}$ & $\mathrm{x}$ & $\mathrm{x}$ & $\mathrm{x}$ & 2.55 & 3.44 & $\mathrm{x}$ \\
\hline$\alpha$-phellandrene & $\mathrm{x}$ & $\mathrm{x}$ & $\mathrm{x}$ & $\mathrm{x}$ & $\mathrm{x}$ & 7.14 & 3.11 & $\mathrm{x}$ \\
\hline
\end{tabular}

Note: $x$ : Not detected

values more than $10 \%$, each produced three, three and two known antifungal compounds, respectively. Contrary, isolates BTF05, WAA03 and WAA02 with six, six and five compounds, respectively, produced less PIDG values (Table 1 and 2).

\section{DISCUSSION}

The results from this study showed that fungal endophytes can produce a variety of volatile compounds. However, less than half of these compounds are of importance in biocontrol strategy as most of the volatiles are non-inhibitory in nature. The identification of potential inhibitory compounds for this study is exclusive to FocR4, thus cannot be generalized for the rest of the pathogens. Nevertheless, some of the volatile compounds detected in this study may have a broad-range of antifungal activity as they were reportedly inhibitory towards other pathogens as well. They include 1-butanol 3-methyl and 1-butanol 2-methyl produced by Gliocladium spp. which has inhibitory effect towards Pythium ultimum and Verticillum dahliae (Stinson et al., 2003). Butyrolactone was also produced by Gliocladium roseum
(Strobel et al., 2001; 2008) and in Aspegillus terreus and has shown inhibitory effect towards the pathogen Botrytis cinerea (Cazar et al., 2005). Other volatile compounds such as $\alpha$-phellandrene, acetic acid pentyl ester and 2-acetyl-5-methylfuran, have also been detected in Penicillium roqueforti (Jelen, 2002), Sordoria fimricola (Wihlborg et al., 2008) and Aspergillus fumigatu (Frisvad et al., 2009), respectively, but their antifungal properties are not well-established.

In addition, since we did not specifically extract and quantify the amount of each of the volatiles produced by the endophytes and their influence on FocR4, we were can only conclude that the presence of these volatiles may have a subsequent impact on the growth of FocR4. Their potency as volatile inhibitors cannot be gauge accurately, although peak area comparisons offered some preliminary understanding. For example, in this study, the volatile 1-butanol 3methyl had peak areas of 21.24 and $14.47 \%$ in isolate BTF07 and WAA02, respectively, but their PIDG values were only 7.14 and $2.86 \%$, respectively. Therefore, 1-butanol 3-methyl is considered as less potent compared to other volatile compounds such as 
$\beta$-butyrolactone. Nevertheless, potency of volatile compounds is best investigated in a separate study where the individual compounds are elucidated and extracted and the concentration determined for a more accurate analysis.

\section{CONCLUSION}

To conclude, our study has shown that fungal endophytes have the ability to produce several types of volatile compounds to inhibit the growth of FocR4. We have also shown that some common antifungal compounds produced by other biocontrol agents are also produced by the fungal endophytes in this study. This suggested that these volatile inhibitory compounds can be exploited for the biological control of FocR4 and may be extended to other various pathogens as well.

\section{ACKNOWLEDGEMENT}

The researchers extend their gratitude to the Malaysian Ministry of Science, Technology and Innovation for the research grant awarded. Also to Prof Dr. Sariah Meon who has availed the use of the FocR4 culture in this study.

\section{REFERENCES}

Adebanjo, A. and S.A. Bankole, 2004. Evaluation of some fungi and bacteria for biocontrol of anthracnose disease of cowpea. J. Basic Microbiol., 44: 3-9. DOI: 10.1002/jobm.200310310

Benhamou, N., S. Gagne, D. LeQuere and L. Dehbi, 2000. Bacterial mediated induced resistance in cucumber: Beneficial effect of the endophytic bacterium Serratia plymuthica on the protection against infection by Pythium ultimum. Phytopathology, 90: 45-56.

Bentley, S., K.G. Pegg, N.Y. Moore, R.D. Davis and I.W. Buddenhagen, 1998. Genetic variation among vegetative compatibility groups of Fusarium oxysporum F. sp. cubense analyzed by DNA fingerprinting. Phytopathology, 88: 1283-1293.

Brooks, D.S., C.F. Gonzalez, D.N. Appel and T.H. Filer, 1994. Evaluation of endophytic bacteria as potential biological control agents for oak wilt. Biological Control, 4: 373-381. DOI: 10.1006/bcon.1994.1047

Cazar, M.E., G. Schmeda-Hirschmann and L. Astudillo, 2005. Antimicrobial butyrolactone I derivatives from the Ecuadorian soil fungus Aspergillus terreus Thorn. var terreus. World J. Microbiol. Biotechnol., 21: 1067-1075. DOI: 10.1007/s11274-004-8150-5
Chanway, C.P., 1996. Endophytes they're not just fungi. Can. J. Bot., 74: 321-322. DOI: 10.1139/b96-040

Chaurasia, B., A. Pandey, L.M.S. Palni, P. Trivedi, B. Kumar and N. Colvin, 2005. Diffusible and volatile compounds produced by an antagonistic Bacillus subtilis strain cause structural deformations in pathogenic fungi in vitro. Microbiol. Res., 160: 75-81. DOI: 10.1016/j.micres.2004.09.013

Chen, H., X. Xiao, J. Wang, L. Wu, Z. Zheng and Z. Yu, 2008. Antagonistic effects of volatiles generated by Bacillus subtilis on spore germination and hyphal growth of the plant pathogen, Botrytis cinerea. Biotechnol. Lett., 30: 919-923. DOI: $10.1007 / \mathrm{s} 10529-007-9626-9$

El-Hasan, A., F. Walker, J. Schöne and H. Buchenauer, 2009. Detection of viridiofungin $A$ and other antifungal metabolites excreted by Trichoderma harzanium active against different plant pathogens. Eur. J. Plant Pathol., 124: 457-470. DOI: $10.1007 / \mathrm{s} 10658-009-9433-3$

Fernando, W.G.D., R. Ramarathnam, A.S. Krishnamoorthy and S.C. Savchuk, 2005. Identification and use of potential bacterial organic antifungal volatiles in biocontrol. Soil Biol. Biochem., 37: 955-964. DOI: 10.1016/j.soilbio.2004.10.021

Frisvad, J.C., C. Rank, K.F. Nielsen and T.O. Larsen, 2009. Metabolomics of Aspergillus fumigatus. Med. Mycol., 47: 53-71. DOI: 10.1080/13693780802307720

Hallmann, J., A. Quadt-Hallman, W.F. Mahaffee and J.W. Kloepper, 1997. Bacteria endophytes in agricultural crops. Can. J. Microbiol., 43: 895-914. DOI: $10.1139 / \mathrm{m} 97-131$

Jelen, H.H., 2002. Use of Solid Phase Microextraction (SPME) for profiling fungal volatile metabolites. Lett. Applied Microbiol., 36: 263-267. DOI: 10.1046/j.1472-765X.2003.01305

Larkin, R.P., D.L. Hopkins and F.N. Martin, 1996. Suppression of Fusarium wilt of watermelon by nonpathogenic Fusarium oxysporum and other microorganisms recovered from a diseasesuppressive soil. Phytopathology, 86: 812-819.

Liu, Y.F., Z.Y. Chen, T.B. Ng, J. Zhang and M.G. Zhou et al., 2007. Bacisubin, an antifungal protein with ribonuclease and hemagglutinating activities from Bacillus subtilis strain B-916. Peptides, 28: 553-559. DOI: 10.1016/j.peptides.2006.10.009

McInroy, J.A. and J.W. Kloepper, 1995. Survey of indigenous bacterial endophytes from cotton and sweet corn. Plant Soil, 173: 337-342. DOI: 10.1007/BF00011472 
Naraghi, L., A. Heydari and F. Azaddisfani, 2008. Study on antagonistic effects on non-volatile extracts of Talaromyces flavus on cotton verticillium wilt disease. Asian J. Plant Sci., 7: 389-393. DOI: 10.3923/ajps.2008.389.393

Pleban, S., F. Ingel and I. Chet, 1995. Control of Rhizoctonia solani and Sclerotium rolfsii in the greenhouse using endophytic Bacillus spp. Eur. J. Plant Pathol., 101: 665-672. DOI: 10.1007/BF01874870

Stinson, M., D. Ezra, W.M. Hess, J. Sears and G. Strobel, 2003. An endophytic Gliocladium sp. of Eucryphia cordifolia producing selective volatile antimicrobial compounds. Plant Sci., 165: 913-922. DOI: $10.1016 /$ S01689452(03)00299-1

Strobel, G.A., B. Knighton, K. Kluck, Y. Ren and T. Livinghouse et al., 2008. The production of myco-diesel hydrocarbons and their derivatives by the endophytic fungus Gliocladium roseum (NRRL50072). Microbiology, 154: 3319-3328. DOI: 10.1099/mic.0.2008/022186-0

Strobel, G.A., E. Dirkse, J. Sears and C. Markworth, 2001. Volatile antimicrobials from Muscodor albus, a novel endophytic fungus. Microbiology, 147: 2943-2950. PMID: 11700345

Ting, A.S.Y., S. Meon, J. Kadir, S. Radu and G. Singh, 2008. Endophytic microorganisms as potential growth promoters of banana. BioControl, 53: 541-553. DOI: 10.1007/s10526-007-9093-1
Ting, A.S.Y., S. Meon, J. Kadir, S. Radu and G. Singh, 2007. Field evaluation of non-pathogenic Fusarium oxysporum isolates UPM31P1 and UPM39B3 for the control of Fusarium wilt in 'Pisang Berangan' (Musa, AAA). Proceeding of the International Symposium on Recent Advances in Banana Crop Protection for Sustainable Production and Improved Livelihoods, Sept. 2007, ISHS Acta Horticulturae, pp: 139-144.

Trivedi, P., A. Pandey and L.M.S. Palni, 2008. In vitro evaluation of antagonistic properties of Pseudomonas corrugata. Microbiol. Res., 163: 329-336. DOI: 10.1016/j.micres.2006.06.007

Wan, M., G. Li, J. Zhang, D. Jiang and H.C. Huang, 2008. Effect of volatile substances of Streptomyces platensis F-1 on control of plant fungal diseases. Biol. Control, 46: 552-559. DOI: 10.1016/j.biocntrol.2008.05.015

Wihlborg, R., D. Pippitt and R. Marsili, 2008. Headspace sorptive extraction and GC-TOFMS for the identification of volatile fungal metabolites. J. Microbiol. Methods, 75: 244-250. DOI: 10.1016/j.mimet.2008.06.011 